\title{
FUNDAMENTAÇÃO FILOSÓFICA DO DIREITO À PRIVACIDADE NO CONTEXTO DA ERA DA SOCIEDADE DA INFORMAÇÃO
}

\section{Alexandre Pereira Bonna ${ }^{1}$}

\section{RESUMO}

Trata da fundamentação filosófica do direito a privacidade, assim como apresenta as tensões e desafios para a sua proteção no bojo da sociedade da informação. Explique a relação dos bens humanos básicos com a privacidade. Aprofunda exemplos de violações da privacidade na sociedade atual: tecnológica, massificada e individualista, com breves explicações sobre as consequências jurídicas.

Palavras-chave: privacidade; bens humanos básicos; sociedade da informação; filosofia; responsabilidade civil.

\section{PHILOSOPHICAL RATIONALE OF THE RIGHT TO PRIVACY IN THE CONTEXT OF THE INFORMATION SOCIETY AGE}

\begin{abstract}
It deals with the philosophical foundation of the right to privacy, as well as presenting the tensions and challenges for its protection within the information society. Explain the relationship of basic human goods to privacy. It delves into examples of privacy violations in today's society: technological, massified and individualistic, with some explanations about tort law.
\end{abstract}

Key-words: privacy; basic human goods; information society; philosophy; tort law.

\section{INTRODUÇÃO}

É inequívoco que todos os seres humanos atribuem demasiada importância a sua esfera pessoal de vida, no sentido de possuir controle e domínio acerca das informações que circulam sobre si, podendo voluntariamente propaga-las ou permitir que alguém o faça. Em outras palavras, as pessoas não querem que algumas de suas informações pessoais sejam expostas, proteção esta que encontra ressonância no campo constitucional (art. 5, X, CF-88).

Ocorre que tal interesse de proteção de privacidade deve ser refletido com maior profundidade no campo da sociedade da informação, que é definida como uma nova forma de organização social que recorre ao intensivo uso da tecnologia da informação para coleta,

\footnotetext{
${ }^{1}$ Doutor em Direito pela UFPA, com sanduíche pela University of Edinburgh. Mestre em Direito pela UFPA. Professor de graduação e pós-graduação do CESUPA e FACI-WYDEN. Advogado. Email: alexandrebonna@yahoo.com.br.
} 
produção, processamento, transmissão e armazenamento de informações, como no uso das tecnologias de computação e telecomunicações, ao passo que informação consiste em um dado ou conjunto de dados em qualquer suporte capaz de produzir conhecimento, podendo ser uma imagem, som ou documento (VIEIRA, 2007, p. 156).

Salienta-se que no mundo contemporâneo a informação é o princípio ativo da sociedade no sentido de que o trabalho, o lazer, a saúde, a educação, a política e economia dependem de informação, motivo pelo qual tem se potencializado a tecnologia na facilitação da coleta, produção, transmissão e armazenamento da mesma, dentro de uma chamada revolução da tecnologia da informação (VIEIRA, 2007, p. 157). Tal sociedade da informação compreende o uso de redes sociais, como o facebook, instagram e twitter, assim como aplicativos, como o whatszap e tinder e lojas de compras online como OLX e Mercado Livre mas, em um contexto mais amplo envolve também os cadastros de consumidores em lojas e hospitais, os dados sobre processos judiciais, débitos fiscais, assim como bancos de dados privados de empregadores e públicos da administração do governo.

Destarte, há uma verdadeira Revolução envolvendo a informação, semelhante às revoluções de Copérnico, de Darwin ou Freud (FLORIDI, 2008, p. 651), pois a informação há décadas era de difícil transmissão, armazenamento e produção e hoje, fomentada pelos avanços tecnológicos, ocupa papel de destaque na sociedade contemporânea, sendo mais importante que a propriedade de bens materiais, como explica de forma pontual Hermínia Campuzano Tomé: "las nuevas tecnologias configuram la información como uno de los valores fundamentales de nuestra sociedade. Estamos caminhando desde una forma de vida assentada en los bienes físicos hacia una centrada en el conocimiento y la información" (2000, p. 20).

Adicionalmente, percebe-se que a ideia de privacidade deve ser capaz de acompanhar as novas formas de violação da mesma, na medida em que o incremento tecnológico da informação possibilitou uma abrangência maior na busca, coleta, armazenamento e disseminação dos dados pessoais, sendo imperioso um estudo como esse artigo para do ponto de vista filosófico resgatar a importância da inviolabilidade da vida privada livre de interferências indevidas.

Assim, os avanços tecnológicos da sociedade da informação no contexto do Estado de Direito, que prima pela proteção de direitos fundamentais como a privacidade, 
promovem grande tensão entre a liberdade no uso dos instrumentos tecnológicos e o interesse de se recolher, ser deixado sozinho e possuir autoridade sobre informações pessoais, sendo pertinente o presente artigo, na medida em que tal choque pode ensejar efeitos indesejáveis no nível ético da sociedade e comprometer o patamar civilizatório do Estado de Direito na tarefa de primar pela proteção de direitos fundamentais.

Essa tensão não é fictícia e hipotética. Por uma pequena amostragem do todo, o Comitê Gestor da Internet no Brasil identificou que 46\% dos municípios brasileiros possuem um computador; o acesso à internet, que em 2005 atingia apenas 13\% dos domicílios, no ano de 2012 alcançou 40\%². Já o estudo realizado Mariana Zanata Thibes (2014, p. 19) concluiu que só no Estado de São Paulo de 1999 a 2011 houve um aumento de $20 \%$ de processos judiciais envolvendo violação de privacidade, o que demonstra que o refinamento dos instrumentos de informação potencializou as possibilidades de ameaça à privacidade.

Como exemplo de conflito, no processo n. 0004031-61.2012.8.14.0201 (2 $2^{\text {a }}$ Vara Cível da Comarca de Icoaraci/PA), a vítima tomou conhecimento por meio de um amigo da existência de um falso perfil em seu nome, oferecendo serviços de prostituição no site de relacionamentos "facebook", que por sua vez demorou sete meses para retirar o perfil falso, sem falar de vazamento de divórcios, ações de alimentos, dados bancários, doenças e exames e as perturbações diárias que os consumidores sofrem com ligações e e-mails de pessoas desconhecidas e vendedores em razão de algum cadastro de loja repassar os dados. Em todos os casos se percebe a falta de controle sobre informações da própria vida, que circulam desordenadamente.

Nesse desiderato, atento à necessidade de resgatar a importância da privacidade no seio dessa sociedade da informação, este artigo aborda, no campo teórico, fundamentos filosóficos da proteção da privacidade como essencial para o florescimento humano individual, assim como, no campo prático, reflete sobre as constantes violações da privacidade no bojo da sociedade da informação a partir de literatura que se debruça sobre a proteção de dados no contexto da sociedade da informação. Nesse ínterim, demonstra que tais tensões podem promover uma crise do próprio Estado de Direito diante do uso contemporâneo das ferramentas tecnológicas, especialmente considerando o seu afã de proteção de direitos fundamentais como limitadores da atividade do governo e dos agentes

\footnotetext{
${ }^{2}$ Pesquisa sobre o Uso das Tecnologias de Informação e Comunicação - TIC Domicílios 2010.
} 
privados, tendo em vista que "los poderes privados constituyen hoy una amenaza para el disfrute efectivo de los derechos fundamentales no menos inquietante que la representada por el poder público" (UBILLOS, 1997, p. 243).

Nesse sentido, ressalta-se que o artigo parte do pressuposto teórico de que a privacidade é melhor compreendida quando se reconhece a pretensão de justiça subjacente a sua correlata proteção, pretensão esta que no presente trabalho é a do florescimento humano caldado nos bens humanos básicos desenvolvidos pela filosofia da lei natural.

Em outras palavras, defende-se que no momento de identificar se há ou não violação da privacidade, o pesquisador deve ser alimentado não apenas pelo instrumental frio do texto legal, mas também e principalmente deve compreender que a racionalidade de proteção da privacidade envolve a pretensão de proteger aspectos essenciais do florescimento humano, os quais são total ou parcialmente fulminados a partir da violação da privacidade.

Nesse viés, qualquer fenômeno das ciências sociais é melhor manuseado quando são compreendidos os fins últimos que subjazem o arquétipo de proteção dos bens existenciais, envolvidos em um complexo empreendimento de promoção do florescimento humano e proteção daqueles bens sem os quais não se vive uma vida plena.

Por conseguinte, quando se compreende a finalidade da proteção da privacidade dentro dos bens humanos básicos, o pesquisador pode desempenhar melhor o seu raciocínio sobre regras de convivência no bojo de uma sociedade complexa, tecnológica, individualista e de risco, investigando o bem comum e o tipo de sociedade que o Estado de Direito deve estar comprometido para a construção do bem viver de todos.

Desta feita, no campo da filosofia e da ética, o artigo explora o referencial teórico de Bebhim Donnelly, John Finnis e Mark. C. Murphy, de modo a fundamentar, na ética dos bens humanos básicos que compõem a proteção da privacidade. Assim, visamos a elucidar e fortalecer tal interesse essencial para o florescimento humano no bojo das complexas relações sociais inseridas na tecnologia, a partir da teoria do pensamento contemporâneo da lei natural, que renova as fontes filosóficas da ética clássica de Aristóteles e Tomás de Aquino. No campo das ciências sociais, utilizaremos literatura variada nacional e estrangeira acerca das constantes ameaças à privacidade no manuseio das tecnologias para ao final concluir sobre a necessidade de resgate da privacidade como pilar do florescimento humano no bojo de uma sociedade tecnológica e individualista. 


\section{BENS HUMANOS BÁSICOS E A PRIVACIDADE}

Antes de adentrar na fundamentação filosófica do direito à privacidade, cumpre destacar que este direito faz parte da proteção do ser humano em relação a bens personalíssimos, ou seja, direitos inatos no sentido de que não são adquiridos. Assim, há uma diferença entre direitos que se adquire (acquired right) e direitos que possuímos pela nossa própria existência (innate right, in personam), estando a privacidade relacionada a este último tipo de direito (são inatos): "direitos inatos são direitos que temos em virtude de nossa própria existência e que não precisamos fazer nada para adquiri-los, como é o caso do nosso corpo, mente e liberdades. Os direitos adquiridos são objeto de escolhas e possuem uma relação externa com a pessoa" (Tradução Livre) (WEINRIB, 2012, p. 222).

Nesse sentido, os bens personalíssimos são manifestações daquilo que o ser humano possui de mais básico e que viabilizam o florescimento do mesmo em seus fins particulares. Daí é que sem paz, vida, saúde, liberdade, honra, imagem, intimidade e privacidade, por exemplo, o ser humano não pode perseguir sem tumultos os seus múltiplos propósitos de vida, pois aqueles constituem pressuposto para uma a consecução de fins individuais, que sempre devem guardar harmonia com os fins dos demais sujeitos da comunidade: "como manifestações jurídicas da liberdade, os direitos fornecem um espaço no qual os seus titulares podem perseguir os seus objetivos pessoais. Estes fins são acobertados apenas se não causar efeito adverso para outros" (Tradução Livre) (WEINRIB, 2012, p. 114).

$\mathrm{O}$ direito natural concebe o fenômeno jurídico a partir não apenas do plano institucional legislativo e jurisprudencial, mas também sob a ótica de uma dimensão ética, calcada na busca pela realização dos bens humanos básicos, que são valores que se relevam como razões para o agir humano de qualquer um, valores básicos estes que se forem respeitados ensejam a plena realização ou felicidade do ser humano (FINNIS, 2007, p. 30/36), chamada de eudaimonia por Aristóteles, felicitas por Tomas de Aquino e realização humana integral por John Finnis (2008, p. 85/86).

O estudo da ética no direito natural identifica o que o ser humano persegue e busca como bom e se apropria disso para estabelecer os fins últimos racionais para o agir, sendo possível conhecer verdades que contribuem para o florescimento humano (DONNELLY, 
2007, p. 126). Nessa esteira, condutas individuais, políticas e arranjos voltados à realização desses bens básicos são virtuosos (éticos) enquanto que as práticas que desmantelam, desrespeitam e despristigiam os bens humanos básicos são carentes de fundamentação ética por não ser razoável não perseguir os referidos bens inquestionáveis e auto-evidentes, assim como por ferir frontalmente o princípio de que o bem dever ser feito (inclusive os bens humanos básicos) e o mal evitado (good is to be done and pursued, and bad avoided) (FINNIS, 2008, p. 80).

A base para a compreensão das características da natureza humana perpassa pela análise de ações guiadas por princípios que direcionam o agir para bens. De tais ações é possível - pelo valor do conhecimento (razão) - extrair valores que completam o ser humano e lhes servem como razões para uma boa conduta e a consequente realização. $\mathrm{O}$ estudo dos bens humanos básicos visa a responder o que preserva nossa natureza humana e promove uma existência plena. Ademais, mais importante do que necessariamente identificar tais bens básicos, é compreender cada faceta de oportunidades e capacidades do ser humano, com cuidado e zelo para clarificar as formas básicas de bem-estar humano, pois é exatamente essa tomada de consciência que permite a normatividade do direito natural em situações específicas (FINNIS, 2011, p. 33).

Destarte, é fundamental compreender esses aspectos da experiência humana que estão presentes nas atividades e deliberações para tomada de decisões, pois todas as ações inteligíveis possuem um propósito em direção a um bem, no seguinte sentido: 1) um ato é racional quando dirigido aos bens humanos a partir da vontade e algumas condutas são instrumentais para atingir esse fim último, como por exemplo no simples gesto de comprar medicamentos está presente o interesse na preservação da saúde/vida; 2) todas as ações inteligíveis têm como objetivo implícito a realização e proteção de algum bem em alguma medida; 3) esses bens não são escolhidos por cada pessoa ou comunidade política, pois são intrínsecos a todos os seres humanos e inerentes à sua complexidade de realização, de modo que a vida não é um recheado de ocasos e fortuitos, mas sim uma rica experiência de escolhas voltadas ao florescimento em suas mais distintas dimensões; 4) o verdadeiro florescimento está conectado com o ideal de realizar bens básicos não apenas na vida particular, como também no convívio em harmonia com os outros (FISHER, 2013, p. 271/275). 
A propósito, esses bens básicos constituem o ponto central de reflexão do direito natural, que possui como elemento nuclear o conhecimento desses bens: 1) o direito natural, primeiramente, se preocupa com as formas básicas de florescimento humano que são buscadas e realizadas nas ações; 2) em seguida, se ocupa com os pressupostos da razão prática, os quais em última instância estão conectados com nos fins máximos (bens humanos); 3 ) por fim, o direito natural se dedica a pôr esse projeto em prática, discutindo proposições morais mais específicas (HALDANE, 2013, p. 41/42).

A presente pesquisa apresentará a aproximação do direito à privacidade com alguns bens humanos básicos desenvolvidas pela teoria do direito natural a partir de Bebhim Donnelly, John Finnis e Mark. C. Murphy. Na tentativa de fundamentar bens que geram racionalidade para qualquer ser humano em qualquer lugar, Bebhim Donnelly observa que existe um desafio relativista baseado na ideia de que abordar a moral do nosso tempo e espaço como base para a racionalidade gera o risco de justificar ações como corretas do mesmo jeito que no passado se julgava a escravidão correta, pois ter-se-á como parâmetros valores efêmeros e do presente. Deste modo, caso a base moral fosse formada por elementos contextuais e contingentes, o que se tem como certo ou errado rapidamente evaporaria com a extinção das contingências. É por este motivo que a referida autora advoga pela busca de uma investigação de bens humanos que fuja das relativizações e consiga trazer elementos de validade moral ligados a ação humana que independem do nosso tempo (2007, p. 125/126).

Assim, Bebhim Donnelly acentua que um completo estudo sobre os bens humanos básicos envolve quatro dimensões do ser humano, cada uma composta por dois elementos conceitualmente em tensão, um necessitando do outro: a) ser (relacionado à existência)/bem (relacionado ao dever); b) capacidade (relacionado a habilidades que temos enquanto ser humano)/atividade (relacionado à praticidade do dever); c) subjetividade (relacionado à perspectiva do indivíduo)/objetividade(relacionado à perspectiva que a dignidade deve ser percebida); d) personalidade (relacionado à individualidade)/política (relacionado à condição essencial sem a qual todas as outras dimensões não têm sentido) (2007, p. 123).

Desta feita, as características do ser (being) indicam que as pessoas existem em si mesmas e ao lado de outros, têm capacidade de interagir e se comunicar, necessitam de recursos do mundo para garantir sua existência, possuem raciocínio, sentimento, além de 
corpo e mente vulneráveis (DONNELLY, 2007, p. 126/127). Tais subsídios fundamentam a racionalidade do arcabouço jurídico brasileiro, o qual possui uma gama de bens jurídicos aptos a proteger essa faceta da vida humana e mostram "verdades essenciais de nossa condição humana que nos puxam para o que nós somos ou podemos ser num sentido pleno" (Tradução Livre) (DONNELLY, 2007, p. 128).

E, no tocante à privacidade, percebe-se a fundamentação a partir do bem de proteção do sentimento, haja vista que a invasão a um conjunto de informação privadas coloca em xeque frustrações, tristezas e amarguras, assim como a capacidade, visto que a invasão de dados e informações retira do indivíduo a possibilidade de escolher com quem compartilhar. A racionalidade inerente ao ser humano representa a possibilidade de uma busca por tais bens: "os bens devem ser perseguidos porque eles representam basicamente a realização humana na vida, comunidade, comunicação, saúde, razão, etc" (Tradução Livre) (DONNELLY, 2007, p. 130).

De acordo com a lista de Mark C. Murphy, existem nove bens humanos básicos que fundamentam racionalmente as ações humanas: vida (life), conhecimento (knowledge), experiência estética (aesthetic experience), excelência em performances gerais e no trabalho (excellence in play and work), excelência nas tarefas do dia a dia (excellence in agency), paz interior (inner peace), amizade (friendship), religião (religion) e felicidade (happiness) (2001, p. 96).

Sobre a privacidade, têm relação os bens da excelência em tarefas do dia a dia e a paz interior. $\mathrm{O}$ bem da excelência em tarefas do dia a dia está bem adequado com diversos interesses juridicamente protegidos como a perda do tempo útil e a violação da privacidade. Destarte, Mark C. Murphy explana que as pessoas programam certas atividades de uma determinada forma (ir ao banco, supermercado, realizar matriculas, pagamentos, comprar um carro), escolhas estas que são racionais e íntegras e estão dentro de padrões de prospecções da vida de alguém. Em outras palavras, esse bem básico exige o respeito ao julgamento prático formulado pelo ser humano. Trata-se do respeito aos julgamentos de ação e escolhas (2001, p. 114). Deste modo, a linguagem da teoria neoclássica da lei natural se interpenetra com a jurídica para robustecer a proteção da privacidade em situações concretas que por ato de outrem se atrapalha o percurso as escolhas traçadas por alguém, as quais podem estar relacionadas a proteção de informações e dados pessoais. 
Ademais, existe o bem básico da paz interior, conexo com a satisfação de desejos triviais e simples que proporcionam bem-estar, tendo em vista que o ser humano necessita de um estado psicológico de equilíbrio e ausência de estresse para a busca até mesmo de outros bens e para o exercício das capacidades humanas (MURPHY, 2001, p. 118/125). Deste modo, o bem humano básico da paz interior se conecta com o bem existencial da privacidade e a violação do direito de ser deixado em paz, como as comuns perturbações com assédio e perseguições de humoristas e jornalistas a personalidades públicas, dentre outros.

John Finnis possui uma lista de bens humanos básicas parecida com a de Mark Murphy e comenta que a razoabilidade prática é um desses bens básicos, sendo um de seus requisitos é o do bem comum e aqui interessa particularmente o bem comum da comunidade política, e, nessa dimensão, há dois significados para o termo. O primeiro representa a intenção de garantir todo um conjunto de condições materiais e de outros tipos que tendem a favorecer a realização, por parte de cada indivíduo da comunidade, de seu desenvolvimento pessoal. O bem comum está relacionado a um conjunto de fatores que dão sentido à colaboração mútua e permitam condições para que os membros de uma comunidade atinjam seus objetivos e propósitos. Aqui os membros não precisam ter os mesmos planos de vida, mas sim todos deveriam ter condições básicas para o seu florescimento particular (FINNIS, 2007, p. 154). Um segundo significado para o bem comum perpassam pela constatação de que a vida, honra, privacidade, liberdade, amizade, saúde, igualdade, dentre outros são bons para quaisquer e todas as pessoas e cada um desses bens básicos são "comuns" no sentido de que "um número inexaurível de pessoas pode participar deles de uma variedade inexaurível de modos ou de uma variedade inexaurível de ocasiões (FINNIS, 2007, p. 156). Consequentemente, o interesse em alcançar tais bens como a privacidade é relevante e bom não apenas para a vida pessoal, mas para a de qualquer pessoa e essa universalidade reforça a normatividade do bem da amizade, no sentido de que o bem que eu persigo também é o bem de outros, devendo existir uma ponte de solidariedade para que se permita a realização integral de todos os participantes de uma prática social, já que "o bem é, como existência, aquilo que dividimos com todos os seres da face da terra" (FINNIS, 2011, p. 34), motivo pelo qual não deve ser relativizada a proteção do dano moral por se tratar de um mendigo, uma prostituta ou um favelado. 
Não é à toa que uma investigação profunda e comprometida da experiência ocidental no trato com o direito a privacidade no Brasil e nos países anglo-saxões de "nonpecuniary damages" a partir de obras de juristas do Brasil ${ }^{3}$, Espanha $^{4}$, México ${ }^{5}$, Estados Unidos $^{6}$, Canadá $^{7}$, Grã-Bretânia ${ }^{8}$ e da Europa em geral ${ }^{9}$ permitirá inferir que bens como a honra, vida, saúde, liberdade, igualdade, integridade psíquica, integridade física, privacidade e sentimentos ligados a perda de entes queridos são comuns a todos os sistemas jurídicos ocidentais em matéria de compensação de danos.

Deste modo, o atentado contra esses bens (básicos do direito natural e também jurídicos), para além de causarem um desequilíbrio injusto que merece reparação pela via da responsabilidade civil, impedem em diferentes graus uma existência plena do ser humano, motivo pelo qual a concepção de que o arcabouço normativo-positivo incorpora a ética do direito natural eleva o papel que os profissionais do direito e cidadãos têm para com esses valores, que estão conectados numa empreitada grandiosa que, ao invés de repelir e conflitar com o ordenamento jurídico, o embeleza, abrilhanta e prestigia, dotandoo de mais sentido e racionalidade, além de contribuir para uma alavancada de repulsa às práticas de apequenamento dos bens integrantes da personalidade humana, como a privacidade.

\section{TENSÕES ENTRE A SOCIEDADE DA INFORMAÇÃO E PRIVACIDADE}

\footnotetext{
${ }^{3}$ ASSIS NETO, S. J de. Dano moral: aspectos jurídicos. Araras: Bestebook, 1998; BITTAR, Carlos Alberto. Reparação civil por danos morais. $4^{\circ}$ ed. São Paulo: Saraiva, 2015; CAVALIERI FILHO, Sérgio. Programa de responsabilidade civil. 10ª ed. São Paulo: Atlas, 2012; FARIAS, Cristiano Chaves de; BRAGA NETTO, Felipe Peixoto; ROSENVALD, Nelson. Novo Tratado de responsabilidade civil. São Paulo: Atlas, 2015; SANTOS, ANTÔNIO JEOVÁ. Dano moral indenizável. $5^{\circ}$ ed. Salvador: JusPodivm, 2015.

${ }^{4}$ PIZARRO, Ramon Daniel. Daño moral: el daño moral en las diversas ramas del Derecho. Hammurabi: Buenos Aires, 1996.

${ }^{5}$ VILLARREAL, Luis Ernesto Aguirre. Integration of punitive damages into countries with a civil law system: Mexico's case. Tulane University (dissertação de doutorado), 2009.

${ }^{6}$ BURROWS, Vanessa K. Constitutional limits on punitive damages awards: an analysis of the Supreme Court case Philip Morris USA v. Williams. Legislative Attorney. American Law Division. Oder Code 33.773, july-2007.

KOZIOL, Helmut; WILCOX, Vanessa. Punitive damages: common law and civil law perspectives. Vol. 25. Vienna: Springer, 2009.

1.1.1 ${ }^{7}$ FRIDMAN, G. H. L. The law of torts in Canada. Toronto: Carswell, 1990.

${ }^{8}$ MULHERON, Rachel P. Principles of Tort Law. Cambridge: Oxford University Press, 2016.

${ }^{9}$ ANTONIOLLI, Luisa; KOZIOL, Helmut; SCHULZE, Reiner. Tort law of the European Community. New York: Springer, 2008; HEIDERHOFF, Bettina; ZMIJ, Grzegorz. Tort law in Poland, Germany and Europe. Munich, Germany: Sellier European Law, 2009.
} 
Estabelecidas as bases filosóficas da proteção da privacidade, dedicaremos agora um espaço para tratar das tensões envolvendo a privacidade e o uso desenfreado da tecnologia no manuseio de dados pessoais.

O primeiro ponto de tensão identificado gira em torno das novas tecnologias de apreensão de dados pessoais que podem gerar efeitos negativos na vida das pessoas, como para prejudicar com apreensão de senhas, paradeiros e endereço, para transformar a privacidade em mercadorias (como nas tecnologias que apreendem as buscas na internet para vender para publicitários), pode ofender a honra das pessoas (quantos parceiros sexuais, quantas demissões, orientações sexuais ou religiosas), pode expor informações que o sujeito gostaria de reservar apenas para si ou seus familiares (doenças, deformidades, conta bancária, débitos fiscais ou em lojas), pode expor os indivíduos a ceder pressões externas que influenciam suas escolhas (HOVEN, 2008).

Nesse desiderato, pertinente a discussão da privacidade na internet quanto ao uso de cookies, que são dados armazenados no computador do usuário sobre quais sites ele buscou, os quais a princípio visam a melhoria dos sites, contudo alguns cookies podem servir para que o comércio conheça os gostos e preferências do usuário para enviar anúncios de um produto que o usuário tenha visualizado recentemente (PALMER, 2005).

Portanto, na atual conjuntura, no momento em que buscam sites e cadastros, são os usuários que deixam inocentemente suas informações pessoais como endereço, cpf, número de telefone, nome completo, na medida em que as redes sociais, aplicativos e sites de compra desejam mais e mais dados de modo a aumentar o valor do site, dizendo que o perfil está incompleto, já que informação é uma das maiores riquezas da sociedade da informação.

Além do computador, verifica-se uma série de outros dispositivos, como telefones outros equipamentos móveis como o GPS, que servem para coletar e enviar mais dados, inclusive de localização, os quais geram o risco de sujeitar a pessoa a perseguições e roubos, caso essas informações sejam vazadas.

Outro ponto marcante da sociedade da informação que possui tensão com privacidade é que quanto mais o setor público e o setor privado se tornam dependentes das tecnologias da informação mais sujeitos estarão a ataques de pessoas mal-intencionadas. Explica-se. O setor privado passou a utilizar como prática comercial tecnologias para a comunicação e o processamento de informações. Do mesmo modo no setor público há um 
incremento no uso de tecnologias para diminuir burocracia, fornecer melhores serviços, reduzir custos e conferir maior transparência.

Nesse afã de supervalorizar a tecnologia da informação "quanto mais um governo e uma sociedade dependem de sua rede de comunicação, maior sua exposição a ataques de hackers, crackers e de organizações criminosas, crescendo crimes cometidos em meio eletrônico" (VIEIRA, 2007, p. 162/163). Nesse sentido, basta imaginar que um simples conserto de um computador ou celular em uma loja especializada pode permitir a intromissão em todos os vídeos, fotos e conversas daquela pessoa, assim como caso uma rede social ou um e-mail fique aberto em um espaço que outras pessoas tenham acesso, facilmente será possível acessar todas as conversas com clientes e diálogos privados, caracterizando uma maior vulnerabilidade de intromissão dada a maior dependência com tecnologias.

Vale ressaltar que no campo digital ocorre tudo que no também existe no mundo real, como racismo, xenofobia, pornografia infantil, difusão de vírus, e, não seria diferente, com a ofensa com a privacidade, a qual obviamente não guarda mais relação apenas com o que foi mostrado no filme Janela Indiscreta (1954), de Alfred Hitchcock, mas sim se concretiza pela invasão de ambientes eletrônicos que armazenam informações pessoais, sendo possível concluir que um dos grandes desafios das violações da privacidade no campo eletrônico está na dificuldade de responsabilização na medida em que os ofensores não necessitam de proximidade física com a vítima, considerando que a internet constitui mecanismo de comunicação de massa que ultrapassa fronteiras nacionais e compõem uma rede mundial, na chamada infraestrutura global de informação (internet). Não existem fronteiras, o fluxo de informações é intenso e transnacional (VIEIRA, 2007, p. 164/166)

Outra tensão diz respeito ao constante risco no campo da sociedade da informação, visto que muitas vezes os consumidores se recusam a utilizar tecnologias devido aos riscos à privacidade. De acordo com Wartofsky (1986) as pessoas podem ou não estar cientes que estão em risco no campo da internet, podendo voluntariamente assumir riscos ou, sem saber dos riscos, acabar se tornando vulnerável à indevida intromissão em sua vida. Nessa perspectiva, Beldad et al. (2011) explica que o compartilhamento online de informações pessoais dificilmente é considerado seguro.

Assim, as decisões e atividades do presente são marcadas pela dependência a danos futuros, a partir de uma "normalização do risco" ou previsibilidade deste no âmbito social. 
"Esta sociedade começa ali onde falham os sistemas de normas sociais que haviam prometido segurança. Estes sistemas falham pela sua incapacidade de controlar as ameaças que provêm das decisões" (GIORGI, 1998, p. 196).

Em face de o saber estar ligado a avaliações passadas de riscos já conhecidos (visão retrospectiva) e de sua incapacidade de racionalizar eventos futuros de riscos desconhecidos (visão prospectiva), mas altamente impactantes, constata-se a perda de confiança nos centros de decisão no tocante a garantia de segurança, de modo que a sociedade convive com uma normalização do risco, inclusive no âmbito das tecnologias da informação.

De acordo com Milne et al. (2004, p. 219) no âmbito online as pessoas estão vulneráveis de três maneiras: 1) os dados em seu computador ou celular podem estar comprometidos; 2) a transferência de dados para um negócio online pode ser comprometida; 3) os dados armazenados pela empresa podem ser comprometidos. Os autores afirmam ainda que, quando estão conectados à internet, as informações em seus computadores pessoais estão cada vez mais vulneráveis a invasões e roubos, sendo possível também invadir discos rígidos e rastrear as atividades realizadas na Internet.

Segundo Milne et al. (2004, p. 217) as "informações dos consumidores estão em risco quando visitam sites ou completam transações online". Os autores afirmam que, quando os consumidores fornecem informações sobre cartão de crédito e informações pessoais para sites, estas informações podem ser interceptadas. Além dessa possível interceptação, ainda existe o risco de que os dados armazenados nos cadastros das empresas sejam roubados pelos próprios funcionários da empresa.

A maior parte das lojas virtuais, aplicativos e redes sociais impõe como prérequisito do uso que os usuários façam um cadastro de suas informações pessoais (SOM;KIM, 2008). Por conta de tal preocupação, os usuários muitas vezes decidem não seguir adiante nas atividades virtuais ou, atento ao risco, preferem fornecer informações pessoais falsas. A preocupação com a privacidade na internet, de acordo com Bélanger e Crossler (2011), mostra que o avanço das tecnologias da informação despertou aguçada preocupação dos usuários com a privacidade das informações e seus impactos negativos, conforme mostra o quadro abaixo:

Em outra pesquisa foram identificadas as principais preocupações dos usuários: a) com a deturpação das informações fornecidas; b) com o acesso das informações por 
pessoas não autorizadas; c) com o uso das informações pessoas para outras finalidades não explicitadas pelo site (SMITH et al., 1996). Tais receios demonstram que o medo de invasão da privacidade ganha novos contornos na sociedade da informação.

Por fim, outra tensão identificada no campo da privacidade na sociedade da informação diz respeito a atos praticados nas relações públicas e privadas que causam dano moral, embora muitas vezes seja difícil a responsabilização, como visto acima. Como se não bastassem as bases filosóficas da lei natural eu justificam a proteção de dados pessoais, a Constituição Federal de 1988 transforma esse comando ético em comando jurídico, ao estabelecer, em seu artigo $5^{\circ}$, inciso X que "são invioláveis a intimidade, a vida privada, a honra e a imagem das pessoas, assegurado o direito a indenização pelo dano material ou moral decorrente de sua violação", permitindo que tal respeito se imponha de forma coercitiva na atuação dos agentes públicos e privados.

Em outras palavras, a proteção da privacidade, para além de ser arrimada no campo ético, também está presente no patrimônio jurídico das pessoas. Nesse sentido, Augusto Zenum (1996, p. 67) acentua que patrimônio é "o conjunto de direitos e obrigações de uma pessoa. Não é, pois, só formado de direitos e bens, mas de direitos e deveres jurídicos". Desta feita, é possível afirmar que faz parte do patrimônio jurídico de outrem o respeito e zelo que este deve ter por bens patrimoniais e existenciais de terceiros, que por consequência, enquanto direitos, estes bens fazem parte de seu patrimônio jurídico.

Por esse motivo Acerca de tal linha de pensamento, afirma-se que surge o direito de indenização por dano moral no caso de violação da privacidade, sendo o dano moral caracterizado como "a lesão ao patrimônio jurídico materialmente não apreciável", como ensinou S. J. de Assis Neto (1998, p. 33). Portanto, quando o direito reivindica para si a tutela de um bem sabe-se que o respeito por esses interesses (agora juridicamente protegidos) se torna obrigatório e coercitivo, excluindo razões pessoais para descumpri-lo. Por fim, em um sentido amplo, dano moral é a violação a um interesse existencial (como a privacidade) concretamente merecedor de tutela jurídica, entendido como aquele que historicamente foi construído por uma comunidade política como digno de proteção (FARIAS; BRAGA NETTO; ROSENVALD, 2015, p. 296).

Embora comumente se dê ênfase aos bens materiais, não se pode olvidar que fazem parte do patrimônio aqueles referidos bens existenciais (honra, privacidade e imagem), que de fato são mais importantes para a plena realização humana e se assemelham ao que a 
Nova Teoria da Lei Natural, capitaneada por John Finnis, intitula de bens humanos básicos, que são valores que se relevam como razões para o agir humano de qualquer um, valores básicos estes que se forem respeitados ensejam a plena realização ou felicidade do ser humano (FINNIS, 2007, p. 30-36), chamada de eudaimonia por Aristóteles, felicitas por Tomas de Aquino e realização humana integral por John Finnis (2008, p. 85-86).

O direito à intimidade e à vida privada estão imbrincados, porque a vida privada é mais ampla do que a intimidade. Desta feita, a intimidade se refere à faceta mais interna e sagrada do ser humano, ao passo que a vida privada tem relação com questões que não são íntimas, mas que fazem parte de um conjunto de fatos que não são de conhecimento da sociedade e podem merecer proteção pelo zelo de a pessoa manter reservadas a si ou a um grupo restrito, fora do alcance de conhecimento dos demais (SILVA, 2005, p. 264).

Nesse sentido, informações sobre como a pessoa dorme, almoça e janta dentro de seu recinto familiar, se a pessoa frequenta bordeis, se está com novo namorado ou terminou o noivado, se vai todos os dias ao encontro da amante, se tem dois ou mais parceiros sexuais não dizem respeito ao seu íntimo mais intrínseco, mas conectam-se com um campo que o sujeito deseja manter confidencial, motivo pelo qual está protegido pelo bem jurídico da vida privada. De outro lado, deformidades, anomalias, fatos desabonadores do passado e/ou vícios que o ser humano possua se referem mais propriamente à intimidade.

Vale lembrar que não será de tanta relevância estabelecer um termômetro que divida o bem jurídico da vida privada da intimidade, pois ambos são igualmente protegidos pela Carta Magna e, em um sentido amplo, se referem à inviolabilidade de a pessoa ter um espaço mínimo reservado apenas para si e com quem queira dividir, ou, nos dizeres de Américo Luís Martins da Silva, trata-se da "liberdade de se introverter, de se recolher à vida privada" (2005, p. 263). Diz respeito a um âmbito que o ser humano deseja manter condutas e situações dentro do espectro privado, sem difundir ao conhecimento de terceiros, como questões ligadas a doenças, a tristezas e frustrações, a hábitos circunscritos ao âmbito familiar, a deformidades físicas, ao cotidiano com os ascendentes, descendentes, cônjuge ou companheira, dentre outros. Em todos esses casos, estamos diante de informações que não possuem relevância significativa para mais ninguém, a não ser à própria pessoa e àqueles com quem queira compartilhar. 
É importante destacar que o espectro de proteção da intimidade é mais amplo do que possa parecer. De acordo com Ramon Daniel Pizarro (1996, p. 501), tal direito está vinculado a uma tripla dimensão: a) direito de ser deixado em paz e tranquilidade; b) direito à autonomia em relação as decisões de sua existência; c) direito de controle de informações pessoais. De tal modo, também está dentro da proteção da intimidade a violação de correspondência, a divulgação de dados pessoais $(\mathrm{CPF}$, endereço, número do celular, etc) para terceiros, assim como a toda e qualquer difusão de informações do íntimo do ser humano.

Cabe destacar que, diferentemente dos ataques à honra, que admitem a exceção da verdade, para as transgressões à privacidade são irrelevantes que o fato veiculado seja verdadeiro ou não. Em qualquer caso, quando por ato de terceiro aspecto reservado ao íntimo do ofendido for divulgado e revelado, ocorrerá a violação da privacidade.

São exemplos de violações aos bens jurídicos intimidade e/ou vida privada no campo da tecnologia: a) divulgação de foto da pessoa agonizando em cirurgia; b) publicação de sentença de divórcio com a identificação do nome das partes; c) divulgação de fotos íntimas da pessoa sozinha ou com seu parceiro; d) violação de correspondência; e) transmissão para terceiros de cadastro de consumidor contento suas informações pessoais; f) vazamento de informações acobertadas pelo sigilo profissional; g) intromissão por fotos ou filmagens no domicílio do ofendido, retratando a intimidade familiar; h) instalação de câmeras dentro de residências ou espaços privados sem a divulgação; i) interceptação telefônica sem autorização judicial, porém observa-se que a gravação de telefonema feita por um dos interlocutores sem autorização do outro não gera dano moral; j) vizinho que tira fotografia da vizinha aos beijos com o novo namorado na saída do elevador e publica para o conhecimento de terceiros; k) divulgação de vídeo capturando momentos do ofendido dentro de sua casa com sua família em diversas situações cotidianas; 1) divulgação de doença ou vício que a pessoa desejava manter em sigilo. Em todos os exemplos acima identificados, houve violação da privacidade como um interesse extrapatrimonial protegido juridicamente, surgindo o dever de indenizar os danos morais causados ao ofensor, sem prejuízo de eventuais sanções criminais.

\section{CONCLUSÃO}


A partir da análise da lei natural percebeu-se que a privacidade está umbilicalmente ligada com o bem humano básico da sociabilidade e da razão prática, no sentido de que só se vive uma vida bem vivida e apta ao florescimento humano se existir harmonia entre pessoas e grupos de pessoas, no sentido de proteção da autonomia e dos dados pessoais, fazendo com que as pessoas sejam senhoras de si mesmas e com capacidade de autodeterminação.

Tal interesse ético está em cheque na era da informação altamente tecnológica, porque o indivíduo liberal moderno é desprovido de um telos comunitário, visto que a modernidade produziu a ideia de ser humano destacado de seus papeis sociais, o que não havia nas sociedades pré-modernas, onde o sujeito extraia seus deveres e obrigações a partir da sua relação com os diversos grupos sociais, visto que o próprio espaço particular do indivíduo só fazia sentido se estivesse em harmonia com as suas relações sociais (MACINTYRE, 1981, p. 33).

Essa ausência de um telos compartilhado na modernidade é gerada em parte pela existência bifurcada de dois campos abertos de vida: a vida social e a esfera individual: "essa dicotomia é uma importante pista sobre uma característica central das sociedades modernas" (Tradução Livre) (MACINTYRE, 1981, p. 34). No aspecto individual, os indivíduos são soberanos em suas escolas relacionadas aos bens que desejem perseguir; no tocante à vida social, a burocracia é soberana nessas mesmas escolhas a ser válida para todos como meio de proporcionar a convivência, com legitimidade inclusive para limitar as escolhas arbitrárias e livres dos indivíduos pela lógica burocrática, que também é emotivista e se pauta na "racionalidade de coincidir meios e fins em termos econômicos e de eficiência" (Tradução Livre) (MACINTYRE, 1981, p. 25).

Nesse sentido, devem os atores sociais se conscientizarem sobre o valor da privacidade não como um meio para alcançar outro fim, como propriedade, segurança, autonomia, democracia, liberdade, dignidade ou utilidade e valor econômico (visão reducionista) (THOMSON, 1975), mas sim de que a privacidade é um valor em si mesmo e sua importância não é decorrente de outro fim a ser almejado (RÖSSLER, 2004) (visão ampliativa), bem próxima das bases dos bens humanos básicos aqui traçadas.

Essa visão substancial revigora e solidifica as bases do Estado de Direito no tocante à proteção dos direitos fundamentais e promoção do bem comum no seio da comunidade política, diante das tensões produzidas pela tecnologia da informação, como as constantes 
violações da privacidade por agentes públicos e privados, o inerente risco de alta magnitude no manuseio de informações pessoais no campo da internet, assim como o grande receio que afeta parte dos usuários das tecnologias. Deve, portanto, o Estado, por meio de leis e políticas públicas, diante desses novos desafios contemporâneos, primar pela criação de mecanismos de proteção dos dados pessoais na internet, assim como devem os grupos sociais se conscientizarem de que o vilipêndio do espaço privado afeta em alguma medida o florescimento humano.

Nesse sentido, como já existem as leis n. 12.737/2012 - que dispõe sobre a tipificação criminal de delitos informáticos - a lei 12.965/2004 - que estabelece princípios, garantias, direitos e deveres para o uso da Internet no Brasil - e a lei 13.709/2018 - que dispõe sobre a proteção de dados pessoais, resta investigar a eficácia de tais diplomas normativos, assim como avaliar se tais mandamentos legais são adequadamente divulgados para a sociedade.

\section{REFERÊNCIAS}

AIYAR, S. The problem of law's authority: John Finnis and Joseph Raz on legal obligation. Law and Philosophy, vol. 19, pp. 465-489, 2000.

ALEXY, Robert. Teoria Discursiva do Direito. Trad. Alexandre Travessoni Gomes Trivisonno. $1^{\circ}$. ed. Rio de Janeiro: Forense Universitária, 2014.

ASSIS NETO, S. J de. Dano moral: aspectos jurídicos. Araras: Bestebook, 1998.

AQUINO, Tomás de. Suma Teológica. Vol. 4: I Seção da II Parte, questões 49-114. Coordenação Carlos-Josaphat Oliveira. $2^{a}$ ed. São Paulo: Loyola, 2010.

ARISTÓTELES. Ética a Nicômaco. Tradução Edson Bini. 2a ed. São Paulo: Edipro, 2007. FERREIRA NETO, Arthur Maria. Metaética e a fundamentação do direito. Porto Alegre: Elegantia Juris, 2015.

BATNITZKY, L. 'A Seamless Web? John Finnis and Joseph Raz on Practical Reason and the Obligation to Obey the Law'. Oxford Journal of Legal Studies Vol IS, No 2. Oxford University Press, 1995.

BARZOTTO, Luis Fernando. 'Direito natural institucional'. In: Teoria do direito. Porto Alegre: Livraria do Advogado, 2017, p. 56-76.

BARZOTTO, L. Filosofia do direito. Os conceitos fundamentais e a tradição jusnaturalista. Porto Alegre: Livraria do Advogado, 2010.

BELANGER, F.; CROSSLER, R.E. Privacy in the Digital Age: A Review of Information

Privacy Research in Information Systems. Mis Quarterly. v. 35, n. 4, p. 1017 - 1041, 2011.

BELDAD, A.; JONG, M.; STEEHOUDER, M. I trust not therefore it must be risky: Determinants of the perceived risks of disclosing personal data for e-government transactions. Computers in Human Behavior. vol.27, n. 6, p. 2233 - 2242, 2011. 
CAVALIERI FILHO, Sérgio. Programa de responsabilidade civil. $10^{\mathrm{a}}$ ed. São Paulo: Atlas, 2012.

CAMPUZANO TOMÉ, Hermínia. Vida privada y datos personales: su protección jurídica frente a la sociedad de la información. Madrid: Tecnos, 2000.

COLEMAN, Jules L. The mixed conception of corrective justice. Iowa Law Review, vol. 77, 1992a, p. 427/444.

257-322.

, Jules. Second thoughts and other first impressions. Analyzing Law, 1998,

DUKE, George. 'Finnis on the Authority of Law and the Common Good'. Legal Theory, vol. 19, pp. 44-62, 2013.

GIORGI, Raffaele de. Direito, democracia e risco: vínculos com o futuro. Porto Alegre: Sérgio Antônio Fabris Editor, 1998.

GONÇALVES, Carlos Roberto. Responsabilidade civil. 11 a ed. São Paulo: Saraiva, 2009.

FARIAS, Cristiano Chaves de; BRAGA NETTO, Felipe Peixoto; ROSENVALD, Nelson.

Novo Tratado de responsabilidade civil. São Paulo: Atlas, 2015.

FINNIS, John. Fundamentos de Ética. Tradução Arthur M. Ferreira Neto. Rio de Janeiro: Elsevier, 2012.

$2011 \mathrm{a}$.

Reason in action. Collected Essays, vol. I. Oxford: Oxford University Press,

Human Rights and Common Good. Collected Essays, vol. III. Oxford: Oxford University Press, 2011b.

Philosophy of Law. Oxford: Oxford University Press, 2011c.

1998.

Aquinas: moral, political and legal theory. New York: Oxford University Press,

Lei natural e direitos naturais. São Leopoldo, 2007.

FLORIDI, Luciano, Artificial intelligence's new frontier: Artificial companions and the fourth revolution, Metaphilosophy, 2008.

GONÇALVES, Maria Eduarda. Direito da informação: novos direitos e modos de regulação na sociedade da informação. Coimbra: Almedina, 2003.

GREEN, Leslie. 'The Nature of Limited Government'. In: GEORGE, R. P.; KEOWN, J. (eds.). Reason, Morality, and Law: The Philosophy of John Finnis. Oxford: Oxford University Press, 2013. p. 186-203.

GRISEZ, Germain. FINNIS, John; BOYLE, Joseph. Practical principles, moral truth and ultimate ends. American Journal of Jurisprudence, vol. 32, 1987, p. 99-151.

CORREAS, Carlos I. Massini. 'La concepción normativa del gobierno del Derecho: nuevas objeciones al rule of law y una respuesta desde las ideas de John Finnis'. Persona y Derecho, vol. 73, pp. 203-230, 2015.

MACINTYRE, Alasdair. After Virtue. $3^{\text {a }}$ ed. University of Notre Dame Press: Notre Dame, 1981.

MILNE, G.R.; ROHM, A.J; BAHL, S. Consumers' protection of online privacy and identity. Journal of Consumer Affairs. v. 38, p. 217 - 232, 2004.

MIRANDA, John Florindo de. Da lei natural como fundamento supramoral da ação humana em John Finnis: Considerações sobre metodologia, teoria normativa e aspectos fundacionais. Dissertação de mestrado. Universidade Federal de Pelotas. Instituto De Filosofia, Sociologia e Política. Pelotas, 2015.

MOOR, J.H.; Towards a Theory of Privacy in the Information Age. Computers and Society.

1997.

Revista Brasileira de Direito Civil em Perspectiva | e-ISSN: 2526-0243 | Belém | v. 5 | n. 2 |

p. 174 - 193 | Jul/Dez. 2019. 
MURPHY, Mark. Natural law and practical rationality. Cambridge: Cambridge University Press, 2001.

PALMER, D.E., Pop-ups, cookies, and spam: toward a deeper analysis of the ethical significance of internet marketing practices. Journal of business ethics, 58(1-3): 271280, 2008.

PIZARRO, Ramon Daniel. Daño moral: el daño moral en las diversas ramas del Derecho. Hammurabi: Buenos Aires, 1996.

RÖSSLER, Beate. Privacies: Philosophical Evaluations, Stanford, CA: Stanford University Press, 2004.

SANTOS, Antônio Jeová. Dano moral indenizável. 5º ed. Salvador: JusPodivm, 2015.

SILVA, Vergílio Ricardo Britto da. Preocupação com a privacidade na internet: uma pesquisa exploratória no cenário brasileiro. Tese de Mestrado. PUC/RS, 2015.

SMITH, H. J.; MILBERG, S. J.; BURKE, S. J. Information Privacy: Measuring Individuals'

Concerns About Organizational Practices. MIS Quarterly, v. 20, n. 2, p. 167-196, 1996. SOM, J.; KIM, S.S. Internet Users' Information Privacy-Protective Responses: a Taxonomy and a Nomological Model. Mis Quarterly, v. 32, n. 3, p. 503 - 529, 2008.

THIBES, Mariana Zanata. A vida privada na mira do sistema: a internet e a obsolescência da privacidade no capitalismo conexionista. Tese de Doutorado. USP, 2014.

THOMSON, Judith Jarvis. The Right to Privacy. Philosophy and Public Affairs, 4: 295314, 1975.

UBILLOS, Juan María Bilbao. La eficacia de los derechos fundamentales frente a particulares: análisis de la jurisprudencia del tribunal constitucional. Madrid: Centro de Estudios Políticos y Constitucionales, 1997.

VAN DEN HOVEN, J. Information technology, privacy, and the protection of personal data". In: Information technology and moral philosophy. J. Van Den Hoven and J. Weckert (eds.), Cambridge: Cambridge University Press, pp. 301-322, 2008.

VIEIRA, Tatiana Malta. $O$ direito à privacidade na sociedade da informação: efetividade desse direito fundamental diante dos avanços da tecnologia da informação. Tese de Mestrado. UNB, 2007.

WARTOFSKY, M. W. Risk, relativism, and rationality. New York, NY: Plenum Press. p. 131-153, 1986. 